\title{
PESSOAS QUE ERAM COISAS QUE ERAM PESSOAS... \\ E CULTIVAVAM, NÃO OBSTANTE, SUAS RELAÇÕES FAMILIARES
}

SLENES, Robert Wayne. Na senzala, uma flor - esperanças e recordações na formação da família escrava: Brasil Sudeste, século XIX. $2^{\mathrm{a}}$ ed. corrigida. Campinas: Editora da Unicamp, 2011. 302 p.

$E_{\text {stiveram cobertos de razão os es- }}$ tudiosos do passado brasileiro que saudaram a publicação, em 2011, pela Editora da Unicamp, da segunda edição do livro de Robert Slenes. Mesmo aqueles há muito dedicados ao tema da escravidão no Brasil dos períodos colonial e imperial, decerto já possuidores de um exemplar da primeira edição, de $1999,{ }^{1}$ entre os quais me incluo, terão acertado ao engrossar essa recepção positiva, quiçá até calorosa.

De fato, é muito bom deixar para trás a por anos infrutífera indicação da eventual compra do livro, por exemplo, a orientandos e demais alunos com o intuito de neles estimular o interesse pela temática da família escrava. Muitos poderão, agora, evi-

\footnotetext{
Robert W. Slenes, Na senzala, uma flor: esperanças e recordações na formação da família escrava, Brasil Sudeste, século XIX, Rio de Janeiro: Nova Fronteira, 1999.
}

tar os exemplares de bibliotecas, inadequados para receber anotações e comentários feitos à margem, algo sempre muito pessoal e imprescindível para vários pesquisadores, bem como dispensar as cópias xerográficas legalmente limitadas tão-somente a frações da obra; ou ainda, economizar o elevado preço que o desequilíbrio entre a oferta e a demanda acarretava para os raros exemplares da edição anterior que vez ou outra surgiam, não por muito tempo, nos catálogos dos sebos.

Some-se a isso um motivo talvez prosaico, mas que duvido se restrinja apenas ao meu caso: é igualmente muito bom deixar para trás a profunda irritação com o manuseio da edição de 1999. Tal irritação advinha do fato de que nela se fez uso de uma cola evidentemente incompatível com a abertura do volume repetidas vezes, causando sua rápida transformação 
num conjunto de folhas soltas, precariamente mantidas juntas, no exemplo do meu volume, mediante o auxílio de um elástico! A Editora da Unicamp sanou esse inconveniente. Todavia, há que fazer o reparo, perdeu a oportunidade de trazer as notas explicativas para o rodapé das respectivas páginas em que foram inseridas pelo autor; em vez disso, manteve o mesmo procedimento da edição da Nova Fronteira. Assim sendo, as notas aparecem listadas ao fim de cada capítulo; como são importantes, portanto não prescindíveis, além de frequentes, acarretam constantes idas e vindas, um estorvo para o leitor.

Esta nova edição tornou-se disponível, pois, uma dúzia de anos após a anterior. Nesse intervalo, todo um amplo contingente de possíveis leitores veio se somar ao e renovar o conjunto dos que acolheram a publicação ao término do século passado. Naquela época, esses novos leitores em potencial provavelmente estavam às voltas com as obrigações escolares próprias do ensino fundamental. Assim, em especial para eles, creio que terá alguma utilidade o esforço no sentido de proporcionar, mediante esta resenha, uma ideia, ainda que sucintamente exposta, acerca da importância que Na senzala, uma flor teve em 1999 e permanece tendo na segunda década do novo milênio.

Vale a pena lembrar, antes do mais, que Robert Slenes, acompa- nhando um movimento de inflexão no que respeita ao tratamento da família escrava ocorrido na historiografia norte-americana, foi um dos pioneiros na introdução desse novo enfoque no estudo das relações familiares estabelecidas entre os escravos no Brasil. De fato, como observei em trabalho anterior, ${ }^{2}$ Slenes, em sua tese de doutorado, defendida em 1976 na Stanford University, ${ }^{3}$ citava as palavras abaixo, de John Blassingame, e apresentava o entendimento de que elas refletiam não apenas a situação dos escravos nos Estados Unidos, mas igualmente a vivenciada pelos cativos no Centro-Sul brasileiro, em especial nas áreas produtoras de açúcar e café:

$\mathrm{O}$ amor que os escravos tinham por seus pais revela claramente a importância da família. Embora fosse fraca e frequentemente separada, a família escrava constituía-se em importante anteparo, um refúgio contra os rigores da escravidão. [...] Em

\footnotetext{
2 José Flávio Motta, Corpos escravos, vontades livres. Posse de cativos e família escrava em Bananal (1801-1829), São Paulo: Annablume / FAPESP, 1999.

3 Robert W. Slenes, "The Demography and Economics of Brazilian Slavery: 18501888" (Tese de Doutorado, Stanford University, 1976). Como sabido, e o próprio título já o indica, as contribuições trazidas por esta tese não se restringiram ao tema da família escrava. E, para o caso de consulta a esse trabalho, foram e são de imprescindível e inestimável auxílio os exemplares existentes em algumas de nossas bibliotecas.
} 
sua família, o escravo não só aprendia como evitar as pancadas do senhor, mas também granjeava o amor e a simpatia dos familiares para elevar seu moral. A família foi, em suma, um importante mecanismo de sobrevivência. ${ }^{4}$

Sem dúvida não era essa a maneira pela qual a historiografia brasileira, até cerca de meados da década de 1970, percebia a família escrava. Dominava, em vez disso, a interpretação segundo a qual pouca relevância, ou mesmo nenhuma, era atribuída às relações familiares entre os escravos no Brasil. Vários foram os argumentos utilizados, ao longo do tempo, para embasar essa perspectiva. Entre muitas outras causas, houve quem aventasse uma alegada inferioridade racial do negro; houve também quem enfatizasse a ação destruidora do regime escravista sobre a organização familiar dos cativos. ${ }^{5}$ Propor-

\footnotetext{
4 John Blassingame, The Slave Community: Plantation Life in the Antebellum South, Nova York: Oxford University Press, 1972, p. 103.

5 Para uma análise mais detida acerca desse enfoque da família escrava pela historiografia, bem como sobre as mudanças nele verificadas posteriormente, pode-se consultar o primeiro capítulo do livro ora resenhado, sobre o qual farei um comentário mais adiante. Pode-se, também, por exemplo, valer-se de José Flávio Motta, "Família escrava: uma incursão pela historiografia", História: Questões \& Debates, v. 9, n. 16 (1988), pp. 104-59, e idem, “A família escrava na historiografia brasileira: os últimos 25 anos", in Eni de Mesquita Samara (org.),
}

cionando um sopro de ar fresco à historiografia, ao passo que evitando exageros revisionistas, escreveu Slenes em sua tese que a família escrava

provavelmente ajudou muitos cativos a conservar sua identidade e a lidar eficazmente com as pressões psicológicas da escravidão. Porém, ao mesmo tempo, ela forneceu aos proprietários das plantations um poderoso instrumento de controle social. $^{6}$

Posteriormente ao estudo de 1976, foram vários os artigos publicados pelo autor dedicados de forma precípua à análise das relações familiares entre os escravos. Destaco quatro deles. ${ }^{7}$ Em todos, foram muitos os resultados e inferências importantes

\footnotetext{
Historiografia brasileira em debate: "olhares, recortes e tendências" (São Paulo: Humanitas; FFLCH/USP, 2002), pp. 235-54.

Slenes, "The Demography”, p. 414.

7 Robert W. Slenes, "Escravidão e família: padrões de casamento e estabilidade familiar numa comunidade escrava" (Campinas, século XIX), Estudos Econômicos, v. 17, n. 2 (1987), pp. 217-27; Iraci Del Nero da Costa, Robert W. Slenes e Stuart B. Schwartz, "A família escrava em Lorena (1801)", Estudos Econômicos, v. 17, n. 2 (1987), pp. 245-95; Slenes, "Lares negros, olhares brancos: histórias da família escrava no século XIX", Revista Brasileira de História, v. 8, n. 16 (1988), pp. 189-203; e Slenes, “A formação da família escrava nas regiões de grande lavoura do Sudeste: Campinas, um caso paradigmático no século XIX", População e família, v. 1, n. 1 (1998), pp. 9-82.
} 
que puderam ser incorporados pela historiografia, diversos deles corroborados e outros questionados pelos demais estudiosos do tema. Na coautoria de 1987, por exemplo, os autores sugeriram que não deveria ser descartada in limine a possibilidade de um eventual crescimento vegetativo positivo nas escravarias de maior tamanho. ${ }^{8}$ Ainda no mesmo número da revista Estudos Econômicos, Slenes observou, em Campinas, nas posses com dez ou mais escravos, serem casadas ou viúvas $87 \%$ das mães, com um ou mais filhos menores de 15 anos e presentes nas listas de matrícula utilizadas como fonte, enquanto nas escravarias menores essa mesma porcentagem era de apenas $37 \%$. Adicionalmente, escreveu o autor,

nos pequenos plantéis, quase todas as mães casadas ou viúvas em 1872 começaram sua vida reprodutiva quando solteiras; [...] nos plantéis com mais de 10 escravos a reprodução humana - e mais ainda a criação de filhos - acontecia principalmente dentro do casamento religioso. Quase a metade das mães teve o primeiro filho só depois de se casarem. ${ }^{9}$

Vale dizer, ao menos parte dos cativos, de uma forma ou de outra, acabava por consumar as ligações

8 Costa, Slenes e Schwartz, "A família escrava", p. 270

9 Slenes, "Escravidão e família”, pp. 219-20. entre si, ainda que talvez à revelia dos senhores e contrariamente aos preceitos da Igreja. Slenes também apontou para a ocorrência de padrões de estabilidade diferenciados das ligações entre os escravos, mais ameaçadas nas posses menores.

Em "Lares negros, olhares brancos", o autor demonstrou como

o racismo, os preconceitos culturais e a ideologia do trabalho da época predispunham os viajantes europeus e os brasileiros 'homens de bem' a verem os negros, que aparentemente não seguiam suas regras na vida íntima, como desregrados. Na segunda metade do século [XIX], quando o 'não seguir as regras' parecia ameaçar cada vez mais a disciplina no trabalho, essa predisposição provavelmente tornou-se mais forte. ${ }^{10}$

Por seu turno, o último dos quatro artigos destacados, numa versão revisada, deu origem ao capítulo 2 de $\mathrm{Na}$ senzala, uma flor ("Companheiros de escravidão: a demografia da família escrava em Campinas e no Sudeste"). Aí encontramos, explorado em toda sua potencialidade, o procedimento tão bem executado por Slenes de cruzamento nominativo de diversas fontes documentais. Nesse capítulo, afirmou o autor,

apliquei o método de ligação nominativa para demonstrar, nas fa-

\footnotetext{
10 Slenes, "Lares negros, olhares brancos", p. 203.
} 
zendas maiores, a relativa estabilidade dos laços entre pais e filhos ao longo do tempo, apesar da ação do mercado de escravos - e, ao mesmo tempo, o duro impacto da mortalidade cativa nessa mesma família nuclear (p. 20).

Desde a tese de doutorado, até o artigo de 1998 que deu origem ao segundo capítulo do livro objeto desta resenha, os trabalhos de Slenes marcaram-se por uma característica distintiva altamente positiva: o competente emprego das ferramentas emprestadas à demografia e à estatística. Trazendo inequívoco contributo ao tratamento quantitativo das fontes primárias, em especial aquelas de natureza seriada, essas ferramentas são muitas vezes meramente descartadas por numerosos estudiosos de nossa história. Dessa forma, a leitura de uma análise como a fornecida no capítulo em tela pode e deve representar um estímulo para os historiadores. Cabe a eles investir na obtenção do domínio ou, pelo menos, dos conhecimentos mínimos que lhes permitam a utilização das aludidas ferramentas demográficas e estatísticas, amiúde elementos ausentes das estruturas curriculares de seus cursos de graduação e também de pós-graduação.

No capítulo 3 do livro ("Esperanças e recordações: condições de cativeiro, cultura centro-africana e estratégias familiares"), o tratamento qualitativo assume posição dominan- te. Com isso, em verdade, o conjunto demonstra de modo cabal como os enfoques quantitativo e qualitativo podem e devem ser aliados, um reforçando o outro na obtenção de um resultado final cuja solidez não seria a mesma se construído apenas a partir de uma dessas vertentes. No referido capítulo 3 , ademais, já se prenuncia o movimento do interesse do autor no sentido de privilegiar questões vinculadas à cultura escrava. Assim, será em especial aí, e tendo por alicerce as inferências obtidas no capítulo anterior, que o autor construirá o edifício de sua interpretação, obedecendo à demanda por ele explicitada no prefácio à segunda edição:

Decididamente, não era possível entender nem as razões (as "esperanças e recordações") nem as ações dos escravizados sem compreender os crivos culturais originais, especialmente os centro-africanos, que ajudavam os desterrados e seus filhos brasileiros a dar sentido à vida - e formar novas identidades - na margem de cá do rio chamado Atlântico (p. 18).

O quarto capítulo ("Lares e linhagens: a flor na senzala") é o último e, por conseguinte, funciona em certa medida como conclusão. Esse fecho é elaborado em torno da interessante discussão acerca do fogo doméstico que os escravos mantinham permanentemente aceso dentro de suas cho- 
ças. Além de um conjunto de razões materiais para esse procedimento dos cativos, Slenes identifica aí a reprodução de prática largamente difundida na África Central, plena de conteúdo simbólico. Valho-me novamente das palavras do próprio autor:

A maioria avassaladora dos escravos trazidos para o Sudeste do Brasil, entre o final do século XVIII e 1850, provinha da África bantu. Entre estes, predominavam largamente pessoas da região Congo/Angola. [...] Por outro lado, até 1850 , quando cessou o tráfico para o Brasil, a grande maioria dos escravos adultos nas regiões de plantation do Sudeste era africana (p. 252).

No Brasil, o fogo doméstico dos escravos, além de esquentar, secar e iluminar o interior de suas "moradias", afastar insetos e estender a vida útil de suas coberturas de colmo, também lhes servia como arma na formação de uma identidade compartilhada. Ao ligar o lar aos "lares" ancestrais, contribuía para ordenar a comunidade - a sanzala — dos vivos e dos mortos (p. 256).

O estudo realizado ao longo dos capítulos 2, 3 e 4 foi enriquecido, ademais, por um capítulo historiográfico, que abre o volume ("Histórias da família escrava"). Embora o autor confesse, no prefácio à primeira edição, ter hesitado em escrevê-lo, "por achar que o assunto, nessas alturas, já era por demais conhecido", enten- do ter sido acertada a decisão de fazêlo. E foi acertada, por um lado, pela razão exposta pelo próprio Slenes, qual seja, em "um ensaio direcionado para um público mais amplo teria certa utilidade, inclusive para dirimir mal-entendidos" (p. 31); motivo, diga-se de passagem, que se fazia sentido em 1999, tornou-se ainda mais pertinente em 2011. Por outro lado, essa incursão pela historiografia mostrou-se oportuna, sobretudo, pelo diálogo crítico esclarecedor inserido na segunda seção do aludido capítulo. Tal diálogo, com uma exposição marcada pela clareza dos principais pontos de discordância, travou-se em especial com as interpretações constantes de dois outros livros, o de Hebe Maria Mattos de Castro e o de Manolo Florentino e José Roberto Góes, publicados em suas primeiras edições, respectivamente, em 1995 e 1997. ${ }^{11}$ Entre os vários elementos de controvérsia figurou, por exemplo, a discussão, com a interlocução voltada para o trabalho de Florentino e Góes, acerca do caráter estrutural da família escrava para a preservação, no tempo, de nossa sociedade escra-

\footnotetext{
1 Hebe Maria M. de Castro, Das cores do silêncio: os significados da liberdade no sudeste escravista \% Brasil, século XIX. $2^{\mathrm{a}}$ ed., Rio de Janeiro: Nova Fronteira, 1998 ( $1^{\mathrm{a}}$ ed. Rio de Janeiro: Arquivo Nacional, 1995); e Manolo Garcia Florentino e José Roberto Góes, A paz das senzalas: famílias escravas e tráfico atlântico, Rio de Janeiro, c. 1790 - c. 1850, Rio de Janeiro: Civilização Brasileira, 1997.
} 
vista. Vale a pena completar esse exemplo, reproduzindo, ainda que numa citação relativamente longa, a posição de Slenes:

Não concordo, portanto, que a família escrava deva ser considerada um fator estrutural na manutenção e reprodução do escravismo [...]. Segundo Florentino e Góes, as "relações parentais" introduziram a "paz" na senzala, isto é, criaram uma nova sociabilidade entre pessoas de procedências diversas, retirando-as de um estado de guerra "hobbesiano", de "todos contra todos", e dando-lhes certo interesse em "tocar" adiante sua vida, sem arriscar confrontos com a casa-grande. De fato, ao formarem tais laços, os escravos aumentaram ainda mais sua vulnerabilidade, transformando-se em "reféns", tanto de seus proprietários quanto de seus próprios anseios e projetos de vida familiar. Isto não quer dizer, no entanto, que foram necessariamente impedidos de criar uma comunidade de interesses e sentimentos e virar um perigo para os senhores. Ao contrário, o refém normalmente tem motivos para identificar-se com outros na sua situação; e não faltam casos, na história, de outros grupos subalternos também, em certa medida, "reféns" dos poderosos - que encontraram o caminho da solidariedade (pp. 59-60).

Um último comentário faz-se pertinente. Essa segunda edição de $\mathrm{Na}$ senzala, uma flor é praticamente idêntica à primeira. Consoante escreve o autor, "resisti à tentação de fa- zer modificações maiores". Não obstante, Slenes elaborou um novo prefácio. Breve, não mais do que dez páginas, todavia muito interessante. Nele, o autor fornece um relato de avanços realizados por orientandos seus, os quais, em dissertações de mestrado e teses de doutorado, muitas vezes corroboraram sugestões e refinaram argumentos do orientador. Uma vez que a formação de discípulos, a meu ver, tem sido outro ponto forte da atividade acadêmica desenvolvida pelo prof. Slenes, o dito relato evidencia, além propriamente dos mencionados avanços, o inestimável papel exercido pela constituição de um competente elenco de pesquisadores ao potencializar os sólidos resultados obtidos pelo grupo.

Em suma, as pessoas que se dedicarem à leitura de $\mathrm{Na}$ senzala, uma flor decerto sentirão, ao seu término, que fizeram uma ótima alocação de seu tempo. Essa nova edição facilita a ampliação do contingente de beneficiários dessa sensação. De resto, e quando menos pelo exemplo de competência no exercício do ofício do historiador, trata-se de leitura obrigatória para os estudiosos do passado brasileiro em geral e, em especial, para os interessados no exame das características de nossa sociedade no período de vigência da escravidão.

José Flávio Motta jflaviom@usp.br

Universidade de São Paulo - USP 
